University for Business and Technology in Kosovo

UBT Knowledge Center

Nov 1st, 5:30 PM - 5:45 PM

\title{
The Influence Of Digital Culture In Tectonics And The Language Of Form In Architecture TOYO ITO, GREG LYNN, PATRICK SCHOUMAKER
}

\author{
Denada Veizaj \\ Polytechnic University of Tirana, denada.veizaj@yahoo.com \\ Gjergii Islami \\ Polytechnic University of Tirana, gjerislam@yahoo.com
}

Follow this and additional works at: https://knowledgecenter.ubt-uni.net/conference

Part of the Architecture Commons

\section{Recommended Citation}

Veizaj, Denada and Islami, Gjergii, "The Influence Of Digital Culture In Tectonics And The Language Of Form In Architecture TOYO ITO, GREG LYNN, PATRICK SCHOUMAKER" (2013). UBT International Conference. 9.

https://knowledgecenter.ubt-uni.net/conference/2013/all-events/9

This Event is brought to you for free and open access by the Publication and Journals at UBT Knowledge Center. It has been accepted for inclusion in UBT International Conference by an authorized administrator of UBT Knowledge Center. For more information, please contact knowledge.center@ubt-uni.net. 


\title{
The Influence Of Digital Culture In Tectonics And The Language Of Form In Architecture TOYO ITO, GREG LYNN, PATRICK SCHOUMAKER
}

\author{
Denada Veizaj ${ }^{1}$, Gjergji Islami ${ }^{1}$ \\ Polytechnic University of Tirana \\ Department of Architecture, Faculty of Architecture and Urbanism, \\ Albania \\ E-mail: denada.veizaj@yahoo.com,gjerislam@yahoo.com
}

\begin{abstract}
The last three decades show how is evolved a complicated relation between architecture and digital technologies, through an absolute skepticism to moments of enthusiasm. The new rhetoric of digital technologies tents to embrace fundamental concepts of architecture, by theorizing another time as in the modern tradition, correlations between form-space-structure. The objective of this paper is to verify the hypothes is which admits that digital culture is changing the relations between space-form and tectonics. In the ambiguous contemporaneity, on the symbioses between spirit and the digital, Toyo Ito's outcome seems to be the one of the most convincing. This paper tents to analyze the Ito's work in the perspective of the new poetics and metaphors deriving from a liberated architecture from materiality. This understanding is made through a comparison between authors as Greg Lynn or Patrik Schumacher that also have implemented in their work the digital technologies but in different dimensions.
\end{abstract}

Keywords : digital technologies, concepts of architecture, , Toyo Ito, Greg Lynn, Patrik Schumacher.

\section{Introduction}

"Digital architectures are profoundly changing the process ofdesign and construction. By integrating design, analysis, manufacture and assembly of buildings around digital technologies, architects, engineers, and builders have the opportunity to reinvent the role ofmaster-builder and reintegrate the currently separate disciplines of architecture, engineering and construction into a relatively seamless digital collaborative enterprise, thus bridging the "gap between designing and producing that opened up when designers began to make drawings. (Kolarevic 2001)

During the last two decades, the modern society has been facing radical developments of the computer science that have transformed it in the so called Information Oriented Society. The implementation of the digital technologies in all processes of our everyday life has caused a great change in our convictions, influencing also researching the nature of the future habitat.

But till now the role of digital tools in the design process is ambiguous. The major part of energy is focused on pure formal is sues. We can mention a lot of authors which celebrates their "synthetic" forms going beyond Euclidian systems. We can find various acrobatic and spectacular forms generated through advanced algorithmic systems which give an uninspected freedom of conceiving and thinking in three dimensions. But till now for describing the relations between form and space we are using the concept of the container separated from the content. The last ten years the possibility of conceiving $3 \mathrm{~d}$ organic shapes, Blobs or Nurbs through digital tools has fascinated the most part of architects. Names as Greg Lynn or Patrik Schumacher are known for their ability on using advanced geometrical systems to generate forms. But till now this process is separated from the debate between forms - spacetectonics. These architects find their solutions in synthetic materials and advanced digital cutters to realize their unusual forms. The involvement of digital technologies on the process tents to avoid this debate by focusing the form poetics only on the non-Euclidian shapes.

One of the most interesting formal interpretations of influence of digital culture on the design process remains the parametrism. 
"It is the elegance of ordered difficulty and the sense of continuous differentiation that relates to natural systems". Schumacher, Patrik: Parametricist Manifesto at 11th Architecture Biennale. Venice, 2008 This reference to nature reminds us what le Corbusier proclaimed about the language of form in modern architecture when the right angle and the straight line are methods through which the man conquers nature. The above paragraph of Schumacher point out a contradiction in the vision of le Corbusier, but not in the need of order, but in the restricted concept of the order related to the Cartesian geometry. The nowadays formal virtuosity is a response towards the complex character of the physical space. Can architecture bee just a geometrical virtuosity? By the other side, can the digital influence on design process produce metaphors on radical compositional themes distant from formal issues? "The language of architecture is built up of signs and symbols (...) specific shape forms and textures have specific meanings" (Hellman 1988)

As long as we talk about signs, systems of recognition or semiotics in architecture it's impossible to not bring up metaphor. As a phenomenon metaphor is a mechanism of analogy in which a concept that belongs to a certain conceptual domain in terms of another conceptual domain is conceived, and in which correspondences between the attributes ofboth domains are established... (Lakoffand Johnson, 1999)

\section{Patrick Schumacher- Digital Culture and the complexity of form}

In parametric design the generation of form is achieved through programming and the process parameterizes and calculates the influence on the form of all the conditioning elements. This complex process of calculations materializes the inputted parameters in architectural form. The Schumacher's latest work tries to give a wider dimension to the debate, from a formal discussion to the effort of conceiving a new methodology to produce architectural space. To evaluate the efforts of this author to improve parametrism from form to philosophy or style, we can see some his notes in his work "Autopoiesis of Architecture" The "Autopoiesis" is a metaphoric term which is related to the selfproduction. The term is introduced in biology in 1970 describing that for each living organism exists a complex closed system which reproduces all its specific components out of its own life process. In analogy architectural or urban systems should reproduce parts of themselves even after their lifecycle. Referring to digital advanced systems and to this theoretical concept Schumacher introduces another time the analogy between the architectural organism and a living one. Contemporary avant-garde architecture is addressing the demand for an increased level of articulated complexity by means of retooling its methods on the basis of parametric design systems." Schoumacher, Patrik: Parametricist Manifesto at 11 th Architecture Biennale. Venice, 2008 The symbiosis between digital technologies and architecture in this case remains enclosed to the generative process of the physical space.

He elaborates the influence of digital culture just on a theoretical plane and in formal terms, avoiding two radical issues; tectonics and materials.

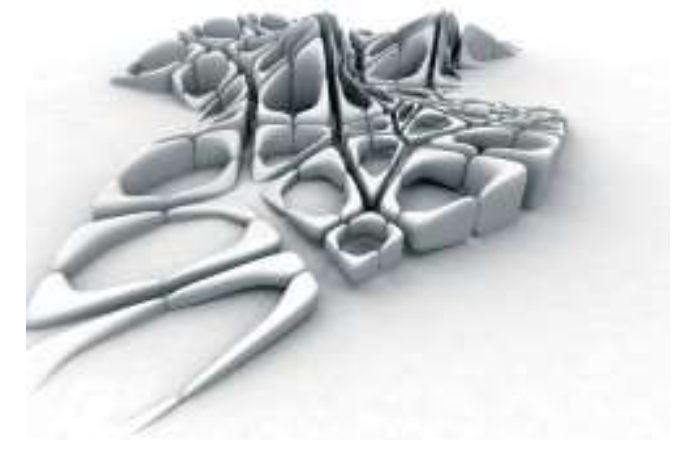

Fig 1.P.Schumacher and Z.Hadid 


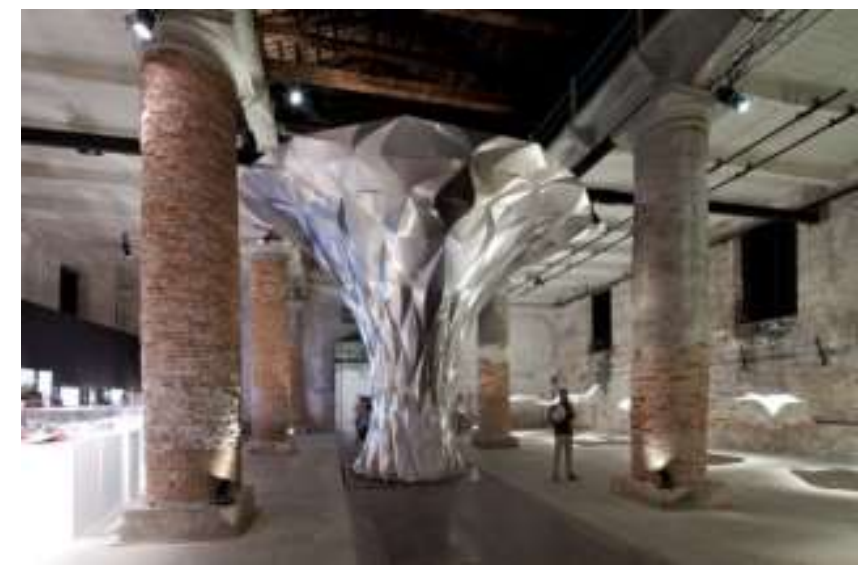

Fig 2 P.Schumacher and Z.Hadid, 2012 Venice Biennale

\section{Greg Lynn - Digital Culture and the Expansion of the Formal Vocabulary}

Through the work of this author, we find another dimension of the symbioses established between architecture and digital technologies which became generators of geometrical systems.

As Lynn admits at the base of his philosophy remains the metamorphosis of the perceptual and geometric model of the nature. Classical geometry was based on ideal numbers and proportional series that were discrete and could be fractionally divided. At the 15 century the decimal point is discovered and another model of seeing nature will be proposed. Today we have a new model of natural formwhich is calculus based and which is using digital tools.

"Line is a curve without inflections"-he says.

"Symmetry is not sign of order, but presence of the missing information" His complex formal vocabulary is based on blobs and folds. Through the work of Grieg Lynn, the form generation process is dependent from the advanced geometry and digital tools. Compositional elements as the pattern will assume new gravity through the involvement of digital methods. The digital tools help Lynn to not see the architectural form in terms of "shapes" or as a "predicted" characteristic added to the organism, but as a process, as a consequence. This is the main metaphoric key to read his work. In fact in all his proposals it is easy to read the "process of form", the dynamism and the movement.

The digital technologies help Lynn to give a new dimension and meaning to the organic and complexity. His organic architecture means holism, proportions, and harmony and synthesis. Syntheses mean intricacy as a relationship, between massing, structure, envelope, aperture, decoration. Natural and organic surfaces are the most interesting examples where pattern, structure and decoration are merged into a complex relation that brings equilibrium.

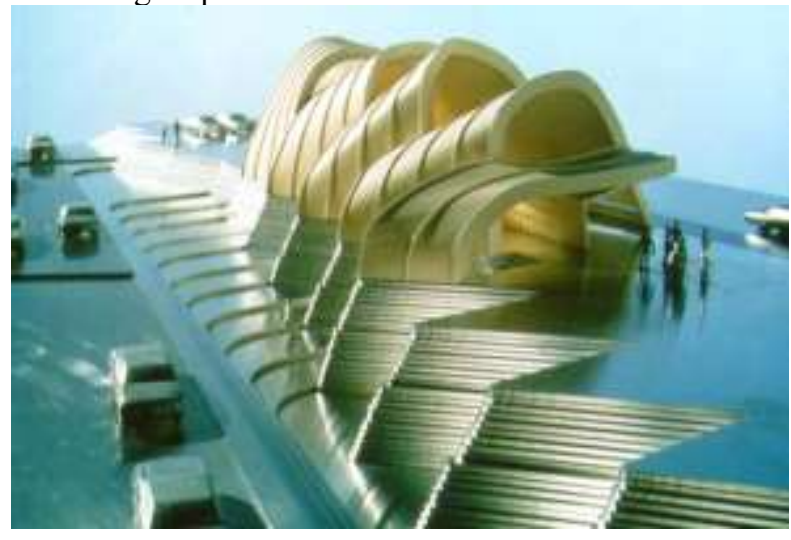

Fig 3 Greg Lynn Hydrogen House 1996 


\section{Toyo Ito - Digital Technologies to Re-dimension the Relations Between Form- Tectonics-Structure}

Toyo Ito is one of the architects who have interpreted in his work all the changes and the new orientations in the design processes in the contemporaneity. This evolution process starts fromthe early ' 80 when he started dematerializing architecture and continues to his nowadays experiments on structures. He tries to find a new dimension of the present by conceiving the structure as the materiality of the nature. This crucial concept of Ito's works is an interpretation influenced at the same time by the Eastern culture differently by the European or the American experience. Ito elaborates a design methodology which derives from his culture. But he is not attracted from the traditional formal language of Japan in the literal sense; he is much more interested in a deeper and intrinsic dimension of his civilization which tents to undo the unnecessary.

Let's see how Ito involves digital technologies in important compositional themes.

The most particular characteristic of Ito's philosophy is that he sees in the use of digital technologies a way to go closer to the nature. And this consists mostly in the reproduction of the advanced natural geometric systems through digital tools and methods. This interest on digital processes is related with his first child experiences with the nature. He is impressed by the nature, by the presence of morphogenetic forms as characteristic of natural reliefs. Beside this, another fact that impresses him is the unstable dimension of natural forms, characterized by the metamorphosis and the continuous change. This will be the most important concept of his architecture, the metamorphosis, fluidity of form from a state to another. "Life source from water"... in a metaphoric plane his architectural creations are born and raised under a continuous formal metamorphosis. In fact, the main remark that he makes to the modern tradition (Corbusier) is about the separation from nature that brought the machine conceived through the pure geometry. The most successful experience of the contemporaneity is the new approach to nature as a possible formal vocabulary. "Now we are duplicating nature much more than in the modern age when we referred to pure geometry by celebrating cubes and spheres. Another radical element that will influence his architectures is the East culture. As he will admit that there are enormous differences in perceiving nature between the East and the West cultures. To his concept, nature is everything, even the buildings or the city, not just plants or the biosphere. His dream is to see an architecture that tends to merge into the nature, to produce architectures that grow under the natural, complex geometrical systems and materials.

In his philosophy the digital technologies are the most important collaborators. The fluidity of formand the need to imitate nature will be supported by advanced geometrical systems. In fact he says that 'due to the technologies there will be not more difference between the people that draw an idea, from that one that realize it. Another time we talk about the digital enterprise of Kolarevic. Now the design phase is separated from the realization in place of the architectural form. Due to the development of digital technologies, there will be a synergy between the two phases. He thinks that this will be the future architecture in the 21 century. The architecture of the $20^{\text {th }}$ century was industrial, the future will bring an "agriculture-architecture" when you "plant a building" by working on the PC. He is an architect that gives a very importance to the form, because of his conviction that architecture is a "sensitive" experience. Now let's see how is materialized in Toyo Ito's architecture this idea of fluidity and natural forms. Let's see how the "emergent grid" as he describes his generative formal system, is a combination of patterns, geometry and structure. The combination of these three elements generates fluid forms. His first important conviction is that the geometry is an internal quality of the structure. He says that for many years his creative activity and his designs were inspired by the phenomena of fluids and movement. Despite the simple geometry used in the early nineties, his work communicates strong notes of formal digital metaphors. In his famous Tower of Winds, he tries to materialize the intangible through digital fluxes. We can easy understand that the metaphor is defined through the metamorphosis of the perception of space/form.

\subsection{The Serpentine Gallery - The skin theme and geometrical metamor phosis}

Let's see how the Ito's work is now focused on structural and tectonic elements. A great exercise on symbiosis between form tectonics and digital algorithms is the Serpentine Gallery in London. 


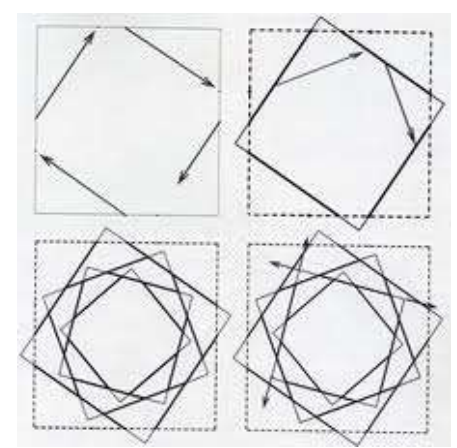

Fig 4 Algorithm of the self-rounded square used in the form generation of the Serpentine Gallery

For more than a century, the modern architecture tried to find balances between form, function, and structure. Now with the use of algorithms, which is a non-lineal process that repeats itself at infinite, we can achieve great structures starting by simple boxes or lines and still talking about balances between form structure and function. This is the way in which both Ito and Cecil Balmond describes their work on the Serpentine Gallery of London. Now the digital formal metaphor is in another level: metamorphosis of a box; escaping from Euclidian geometry. From his earlier works to the newest, his design methodology is structured by a process that starts from the concept to the form. His atelier is still understood as a laboratory when he can use simple materials to realize his models. All his designs go under a selective process which "cleans" all the unnecessary at the aim of generating a pure and very clear concept. His work brings to us another time the der Rohe's poetics of "less is more", but this time under the eyes of the digital generation. He considers digital technologies as tools that help to minimize the use of materials in structures. This fact is also influenced by his culture. His atelier is plain of Origami models. He sees his dream of contemporaneity becoming reality in this simple paper converted in a solid 3-dimensional structure. Technology is not a neutral tissue, is the mechanism which modifies our way of creating social relations. Ito's architecture tents to be liberated from the materiality and the gravity. It's a new poetic which put on a critical position our traditional concept of tectonics. In this point of view Ito sees in the Pavilion of Barcelona of Mies one of the most enthusiastic example of the past century. Through the extension of horizontal planes Ito sees the beginning of his interpretation of fluidity. He is not surprised by the plastic of the steelpilasters but by the incredible merging of materials and space.

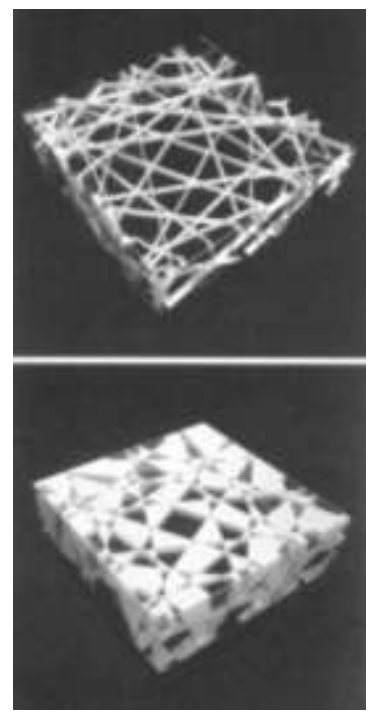

Fig 5 3d-models used in the form generation process of the Serpentine Gallery

Afterward Ito will elaborate a narrative which tents to privilege the effect of the intangible more than tectonics. The research on the relation between tectonics and fluidity is much more developed in his 
proposals of the Serpentine Gallery. In this work is introduced a new era where art, mathematics and abstraction are merged together. His philosophy is developed through his $3 \mathrm{~d}$ models but the spatial outcome is developed through digital technologies.

By discovering the Ito's work we can find some interesting resemblances with the National Gallery of der Rohe. During his work in America Mies brought another time in his rhetoric an important debate on typology, space and structure. The difference this time is the presence of the steel technology of the '50-60. It is a main conviction of his work that the architect is at the same time responsible of the structural issues and should be concerned about tectonics. At his pavilion of berlin he proposes an internal space free from the vertical pilasters. This free box is positioned on 8 pilasters. This concentration on structure and tectonics in fact brings the theoretical debate in other terms. We see a similar attention to structures and tectonics in the Ito's work. But if in the first case tectonics is the poetry of materiality, in the second case structure is used for dematerializing architecture. Toyo believes that only through structures he can liberates architecture from materiality.

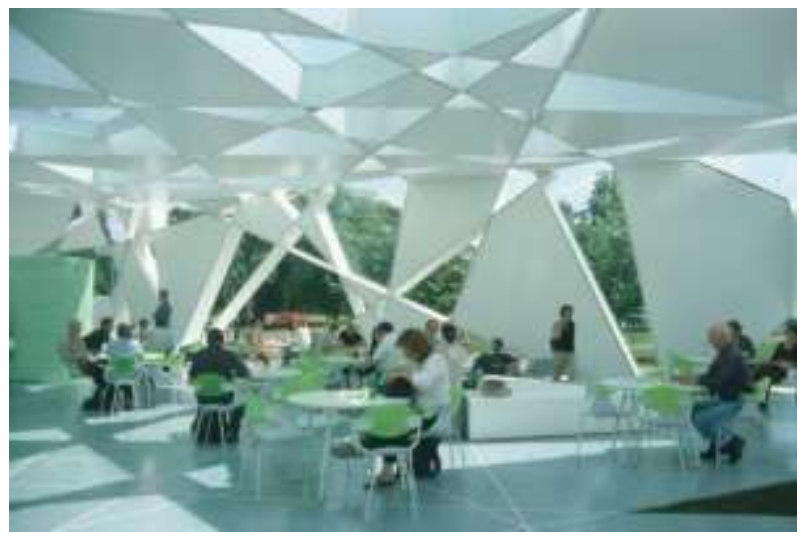

Fig 6 Serpentine Gallery

Toyo in collaboration with Cecil Balmond of the Arup society elaborates the algorithm of a square that expands during his rotation. Diagrams visualize the intersection and the multiplication of real and imaginary lines. The final outcome arrives through a process which select over many proposals. It's about a box of $17.5 \mathrm{mx} 17.5 \mathrm{~m}$ plan and $5 \mathrm{~m}$ height. At the same time digital tools are used to calculate the thickness of steel elements that in this case are $55 \mathrm{~cm}$. In difference with der Rohe in this case not only the internal pilasters are missing. Even Mies tried to liberate architecture from internal structures by adding new space definitions, he could not separate from their tectonic connotations elements as pilasters, horizontal planes etc. In the Ito's work structural elements are merged with space limits elements generating new definitions on interior-exterior relations.

As a virtual limit is light that defines space qualities. Ito uses technology in favour of a narrative. His poetics tents to correlates architecture to our perceptive capacities. To perceive his architecture is not required a material experience. It's not the same experience with the visitor of archaeological sites which tents to touch everything to accomplish his perceptions. The dialog body-perception in the Ito's architecture goes over the materiality in a much more deep intangible dimension.

\subsection{The TOD'S Gallery - The skin theme and fractals algorithms as natural geometric system}

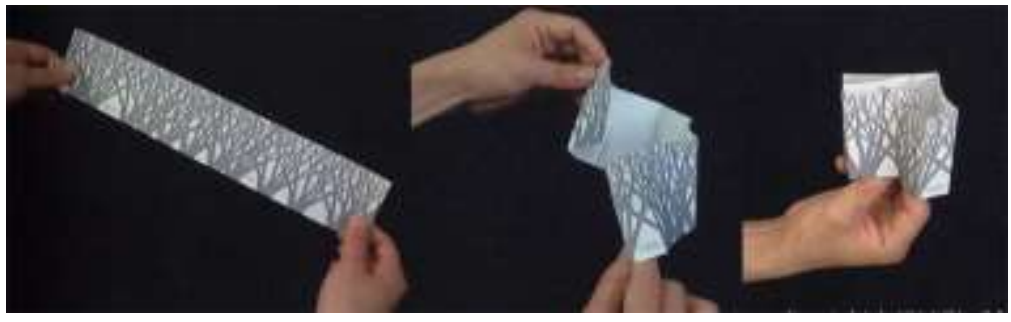

Fig 7 Conceptual phases of the design process 
"Trees are organisms that stand by themselves, so their shape has an inherent, structural rationality" Toyo Ito

Here we find another interesting example of the skin theme.

The skin of the building becomes the most important symbolic element in the conceptual level. Here we can read his strong reference to natural forms, as wonderful systems when formand structure creates the perfect harmony. In this façade we see evolved the fractal algorithm of the recursive subdivision of the primary shape. The branch algorithm is the celebrative image of the fractal structures.

This plane "printed" version of the branch fractal algorithm became a strong element of identity of this building in the immense urban tissue of Tokyo. At the same time celebrates the Ito's reference to natural systems by escaping another time to Euclidian Systems. The metamorphos is of the box container from a Euclidian space to a fractal system generates the metaphor of the digital design.
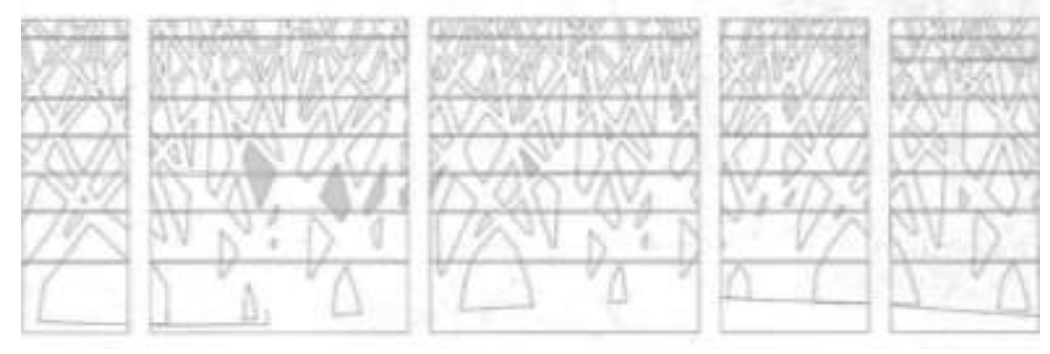

Fig 8 Conceptual phases of the design process -tectonic facades

This skin, interpreted in the tectonic point of view is transfigured in a gradual way from the bottom to the top of the building. The thickness of the structural elements is bigger in the ground floor and began diminishing progressively to the top, by the logic of the recursive repetition and division of the concrete elements.

\subsection{The Sendai Mediatheque - Box metamorphosis}

Another time, nature remains the principal compositional theme of his work. Another time, the metamorphosis of a transparent box merged in the intense centre of Sendai as a giant aquarium of flows becomes the winning concept of a wonderful architectural "creature". The fluidity becomes the compositional order of space. Algorithmic and latticed "tubes" flow vertically through the box becoming transporters of energy, movement and light. For more than a century the structure was considered "a dead" party of the functional space, and in this proposal Ito implant function into those structural tubes, establishing in this way a new equilibrium. The formal metaphor is defined by the analogy established through the space morphology of the cube and the one of a living organism.

Ito mentions Cecil and his concept about geometry as a trace of moving points. This is a conceptual start to add dynamism to those rigid geometric elements.

In this case we can see another metamorphosis of a box, but now in a much more complex dimension. In difference from the first case (Serpentine Gallery) the Ito's energy is focused in the internal space of the box, not just in the skin.

In the Sendai's project we can see being elaborated some interesting theoretical issues that concerns Ito's philosophy. Here for the first time we can see materialized his convictions about the intangible dimension of the phenomenon of the city or the human body. Let's see how digital calculations transform a rigid structure to a living aquarium. Another theme elaborated from Ito is the dematerialization of the architecture. Through his designs, we see how he uses technology to fade the space limits by conceiving the architectural building as a compressed entity of energy and fluxes. How are treated in the optic of the digital culture themes as tectonic form and space in the Ito's work? 


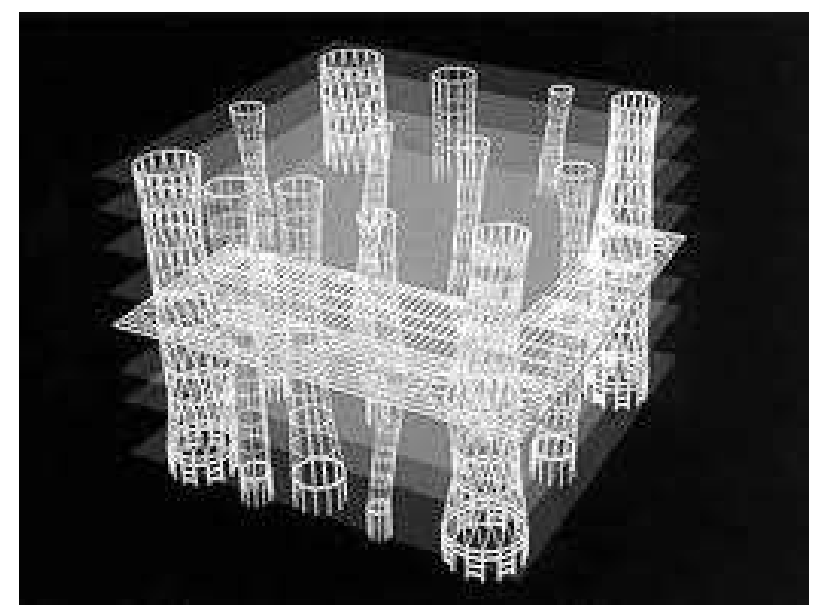

Fig 9 Conceptual rendering of the digital structure

As we saw in the Serpentine Gallery, in difference from other contemporary authors that ignore the tectonics as a constraints or element that influence form, Ito sees in the structure the physicaldimension of the form. This is the reas on of Ito's interest in structural is sues.

The body is an entity of fluids. An interesting phase of the Ito's work will be his essays in finding new ways to understand the human bodies. In his notes on "the human body considered as a fluid" he underlines the idea of a deep analogy between the human body and architecture. From the Vitruvian system of understanding the human body by spheres and squares proportions he passes to a contemporary interpretation of the living organism as a compressed energy. In the classic vision, the body is considered in a quantitative way and exteriorly. There is nothing about the inside human body, about the morphology or about understanding him as a structured system. The word Fluid will be a key word in his creative philosophy. The concept of "Fluxes" will "affect" also his ideas about the city. Since the 80 in his works the city is described as an entity composed by two dimensions; the material or the physical dimension and the virtual, the information and the intangible one.

As we can understand there is another analogy made by him between the human body and the city. From the geographic Vitruvian understanding of the city we pass to the concept of the fourth dimension, of the movement, of the city of fluxes. Ito admits that more than ever his concept of the city is going far from the material dimension. The intangible dimension is generated from lights of energy which nourish a fading reality. The nowadays cities have an intangible component which is virtual or phenomenological and distant from the materiality. He makes a similitude to the city as a transparent plastic film.

In fact one of the most interesting topics derived from the involvement of digital technologies is related to semiotic systems or metaphors due to their influence mostly in the vanishing of geometrical limitations.

\section{Conclusion}

Digital technologies are changing relations between form-space and structure in architecture. There are different answers by architects to this phenomenon due to their cultural ambiance. North American and Occidental architects propose a digital architecture much more focused on formal issues. By the other side an alternative answer arrives from architects of the East culture by involving the digital in a deeper dimension concerning the materiality, the metamorphosis and the space limits.

\section{References}

1. Marotta, A.: Toyo Ito - Construire il Vuoto 
2. Frampton, K.: Poetica della forma architetteonica nel XIX e XX secolo. 2007

3. Kolarevic, B.: Designing and manufacturing architecture in the digital age. 2001

4. Schumacher, P.: Parametricism as a style-Parametricist Manifesto 11th Architecture Biennale. Venice, 2008

5. Aish, R. Kilian, A. Hudson, R.: Fundamental concepts for parametric design. With Grasshopper

6. Schumacher, P.: -Autopoiesis of Architecture -Volume 1, A New Framework for Architecture, published by John Wiley \& Sons, 2010

7. Schumacher, P.: On Parametricism - Let the style wars begin- Article on Architects Journal.co.uk

8. Lynn, G.: On calculus in architecture

9. Lynn, G., Rashid, H.: Architectural Laboratories - NA 2002

10. Lynn, G.: Intricacy, Pennsylvania University Press 2002

11. Sacchi, L., Unali, M.: Architettura e cultura digitale

12. Source of Images

13. http://glform.com/

14.http://aroundarch.wordpress.com

15.http://www.toyo-ito.co.jp 